\title{
Effects of thermal losses on the heating of a multifunctional LTCC module for atomic clock packaging
}

Vecchio F., Slater C., Maeder T., Ryser P.

EPFL (École Polytechnique Fédérale Lausanne)

LPM (Laboratoire Production Microtechnique) 


\section{Outline}

- Introduction: LTCC technology and atomic clock

- Work performed and results obtained

- Discussions and future improvements

- Conclusion 


\section{Introduction (1)}

- LTCC: Low-Temperature, Cofired Ceramic

- Sheets of sintered ceramics (blue, white or black)

- You're carrying it unaware (mobile phone, car ignition)

- Relatively new material (<25 yers, mainly a mixture of glass and ceramics)

- Developed for highly integrated electronics

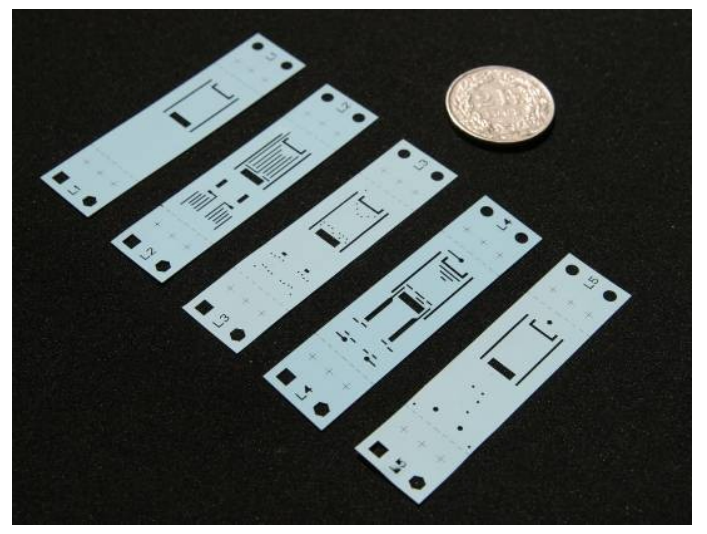

raw sheets of $L T T C$

(micro-reactor)

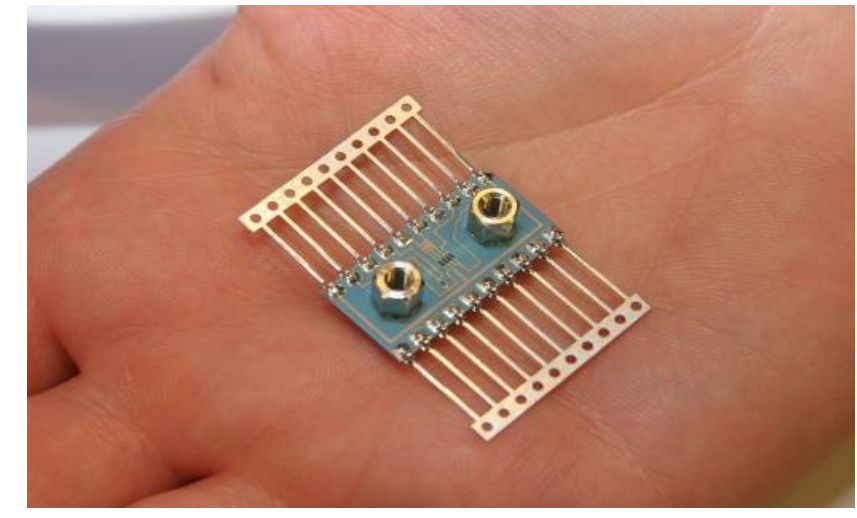

micro-flow sensor assembled

AMS '11

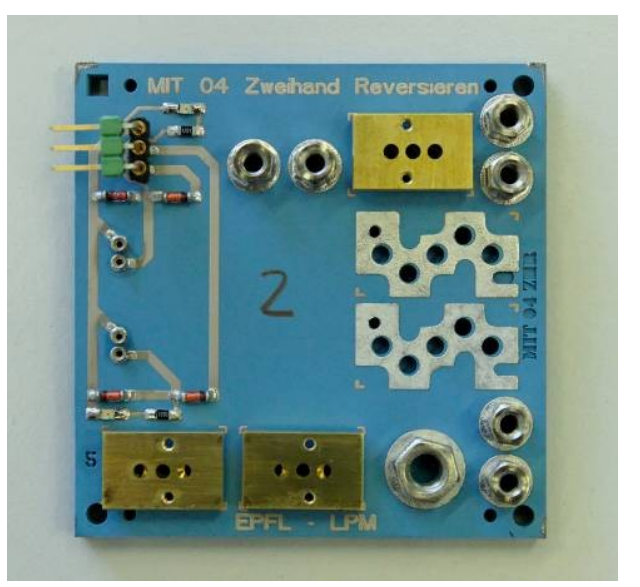

fluidic circuit, management of valves with SMD electronics 


\section{Introduction (2)}

- Atomic clock: what it is?

> It provides the most accurate time measurement

> It is the base for GPS and navigation system

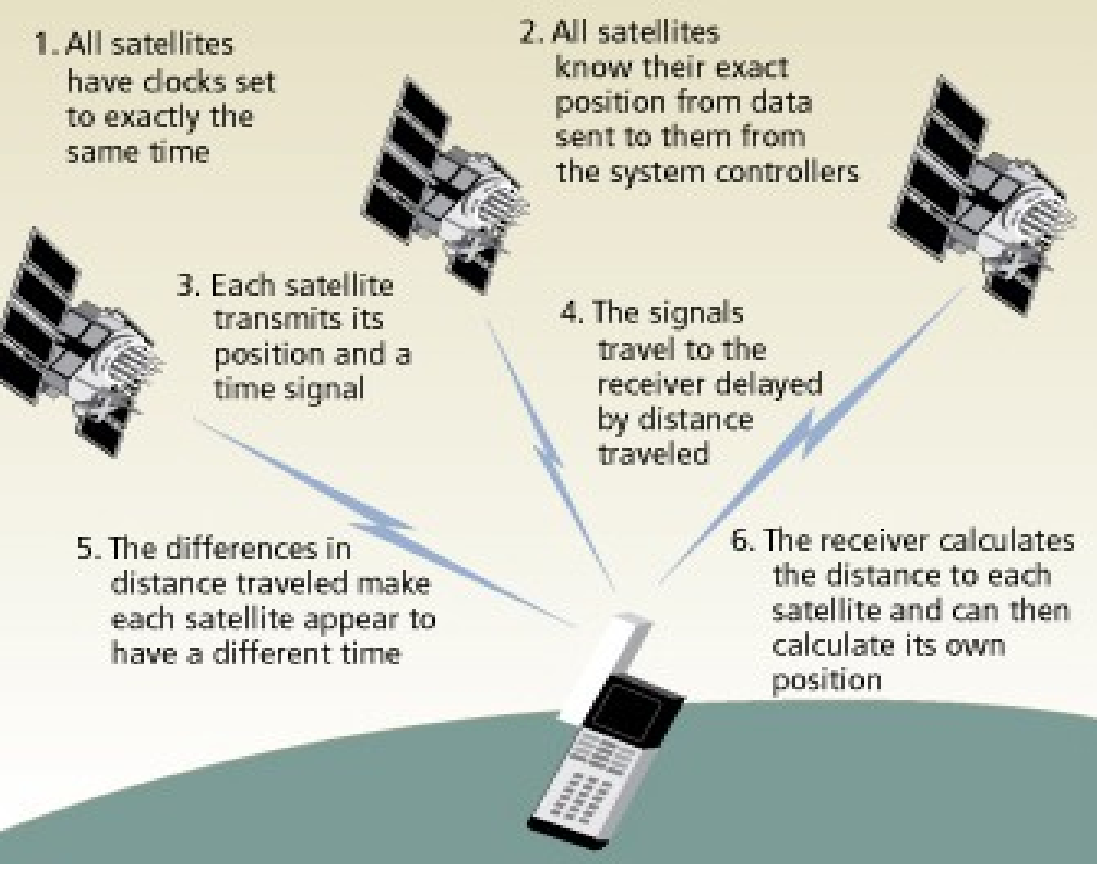

The GPS principle of functioning

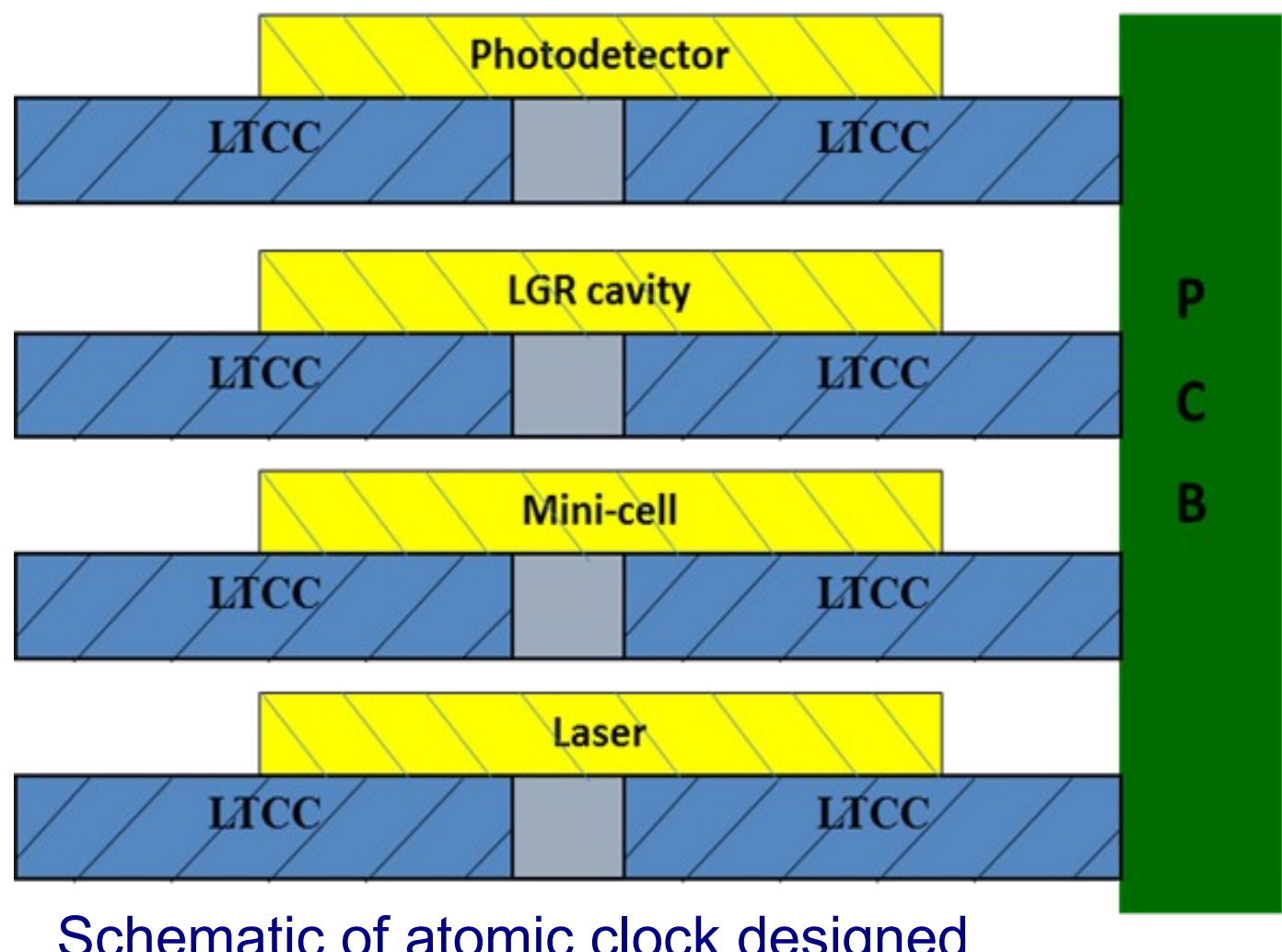

Schematic of atomic clock designed 


\section{Work performed (1)}

- LTCC module realized for packaging of miniature atomic clock

> Temperature measurement and control integrated in the module

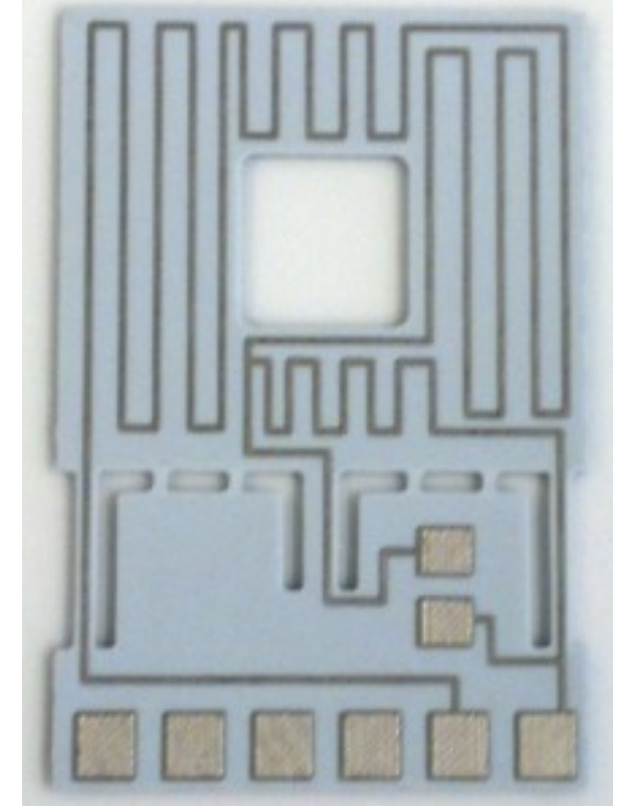

Top of the LTCC module developed: heating serpentine

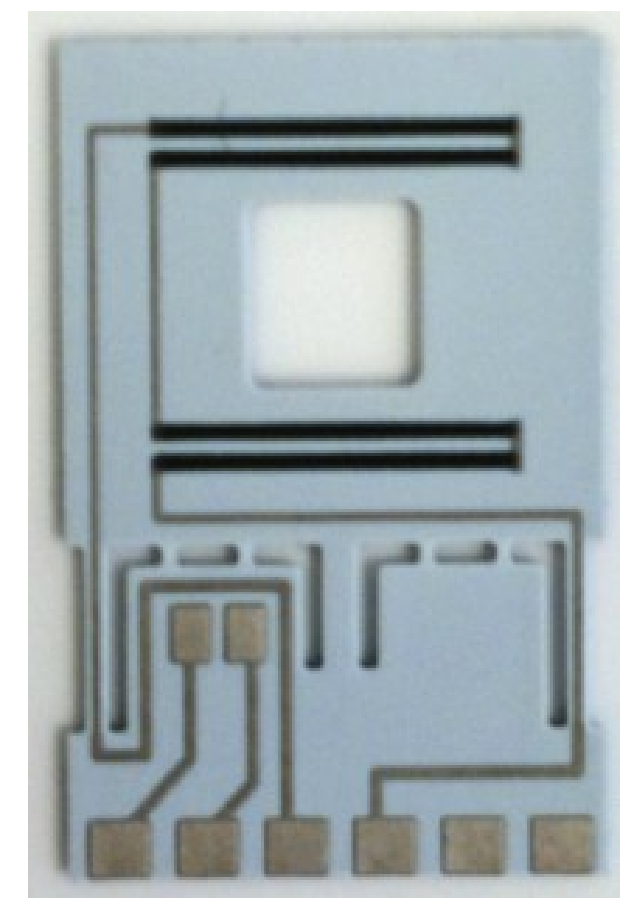

Bottom of the LTCC module developed: PTC resistor 


\section{Work performed (2)}

- Platform to measure thermal conductivity of materials has been developed

- Various insulating materials were characterized and used in experimental heating configuration

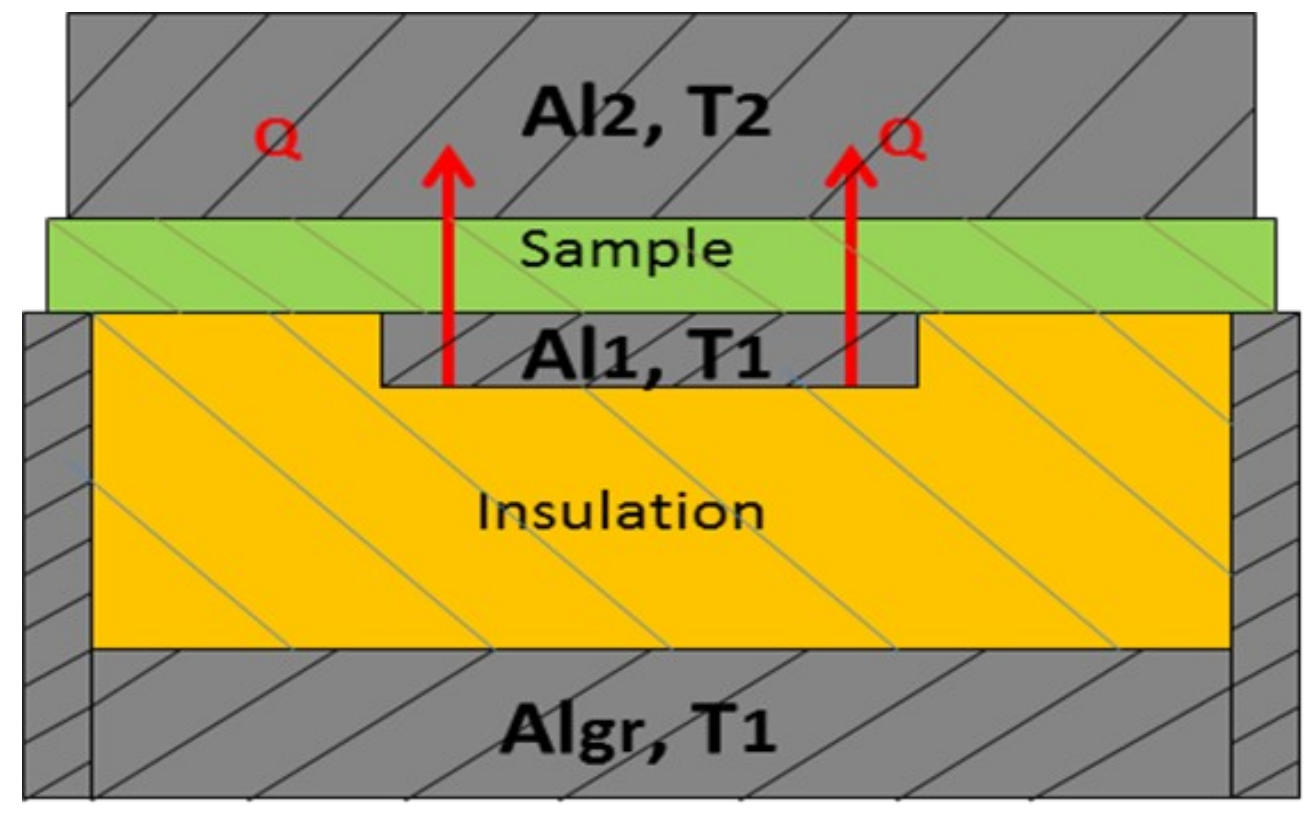

$$
Q \approx-\frac{k\left(T_{1}-T_{2}\right) * S}{h}
$$

Platform for Thermal conductivity measurement developed 


\section{Work performed (3)}

- Thermal characterization of the module

> Evaluation of the influence of the convection and conduction losses to the heating performance

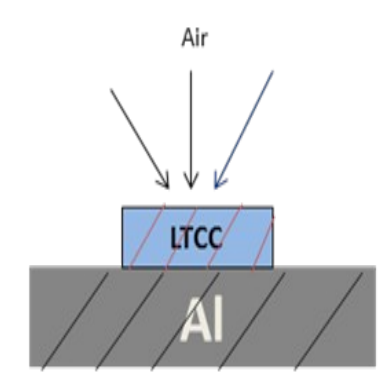

a)

Air

$\downarrow \downarrow \downarrow$

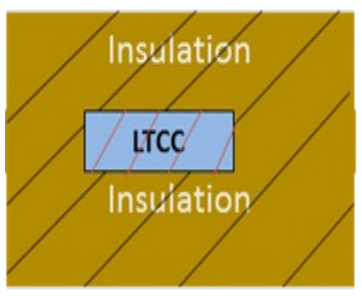

d)

Experimental configurations tested

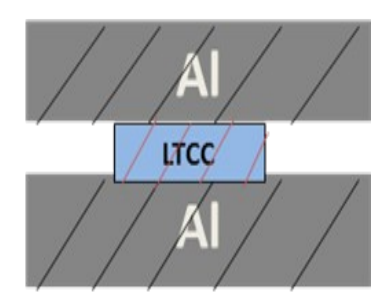

c)

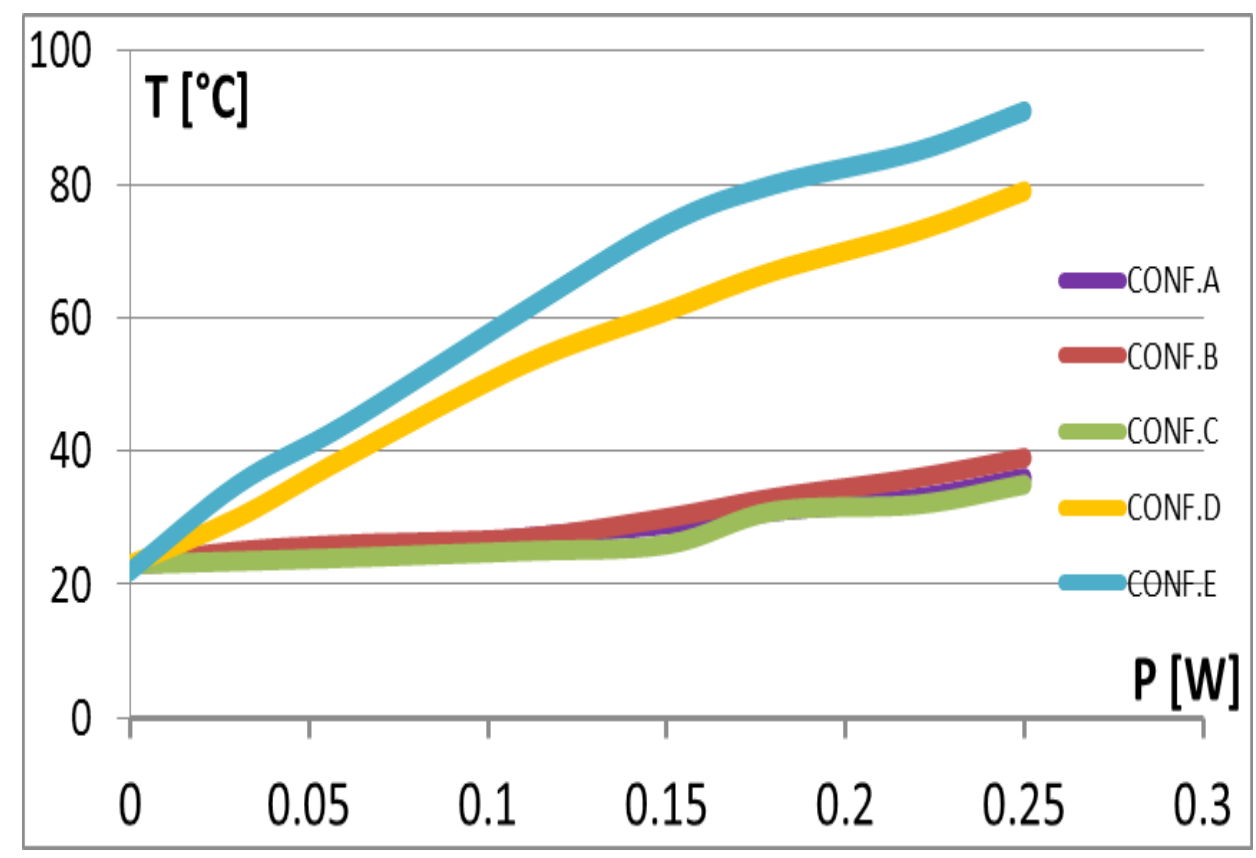

Experimental results 


\section{Discussion and future improvements}

- Ideal temperature calculated and compared with our best heating performance

- Ideal case is when the only thermal loss is the conduction through the small LTCC bridges (complete vacuum, no radiation)
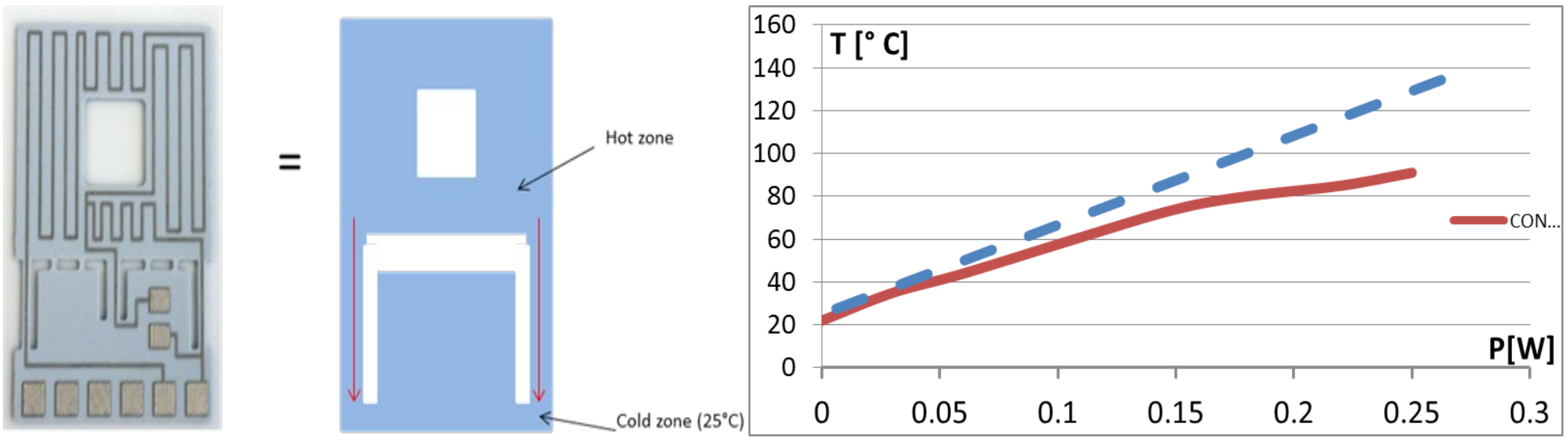

Graphical representation of ideal case

Comparison between ideal case and our better heating performance 


\section{Conclusion}

- LTCC module for miniature atomic clock packaging conceived, fabbricated and tested

- Thermal conductivity measurement system conceived, fabbricated and tested

- Thermal studies of the packaging shows that LTCC is very attractive technology for such application, if efficiently insulated

- Further improvements still possible,especially at high temperatures 


\section{Thank you very much for the attention Questions?}

